\title{
Helping Aesthetics Students in Debremarkos College of Teachers Education
}

\author{
Atalay Mesfin Anteneh \\ Department of Aesthetics and Physical Education \\ Debremarkos College of teachers Education \\ Music teacher \\ Ethiopia
}

\begin{abstract}
The primary objective of this study was to draw mechanisms which have used to improve music student's piano performing skills and sound identification. The problem that faces on the students was lack of practice because of having lack of piano in their class. In order to solve the existing problem the researcher have used three different mechanisms that is preparing handmade piano, adjusting their mobile to rehearse the sound with the position of their finger, adjusting additional class out of their credit hour and using computer rocket system was the main solution used to develop students skill of piano playing and sound identification. The following results was found due to my intervention that is increase sound identification abilities per two tetra chord and put press their finger position on piano. The results were evaluated by using tables' observations when they perform piano and using photograph to cheek changes in their finger position and analyze their change by using tables. For future practice the researcher have planed that searching another best solution for the unsolved problems like problem of identifying more than one octave.
\end{abstract}

\section{Keywords}

Finger practice, sound identification, artificial piano, mobile, rocket system

\section{INTRODUCTION}

Reading of musical notes and playing piano is a very complex motor task which requires years of practice. College facility problems, lack of musical instruments and overcrowding of students are just a few of the many problems. College students face in relation with piano training. Social services and basic utilities in the poorest areas are unreliable at best, causing harsh living environments that are often polluted and unsafe (Kozol, 2006, 1991). College buildings suffer from the same problems as their local communities related with music and art buildings; for example, in one college area the teaching system was notoriously defective, and this caused frequent and regular raw sewage backups in both the students' homes and in their colleges practical skills (Kozol, 2006, 1991). So the activities of music are performed by piano in our college context.

All piano courses were covered by practical way of teaching by using piano. The two essential part of teaching piano is finger practice and sound identification. then, in order to practice many piano needed but, in our department we have only five piano for 40 students when we calculate the ratio of instruments per students and credit hour it becomes once a month for each student, but the objectives put on the course content could not be achieved in such away. Then the only means that the researchers have was finding a solution by cooperating with the students. The above reason initiates me conduct this action research.
Individuals are the main source of improvement of the society and sustainability of its presence if they grown up appropriately. Education being a bridge between human and the life is impressed and shaped by the developments of era, so education of individuals become important parallel with the progress and changes in the society.

Teachers should plan piano education with respect to their students. For a qualified music education, the curriculum should be planned according to the interests of students. It does not only motivate students but also make them learn the subject in an effective way. So they are used wisely; and develop and understand the interdependence among people at local, national and global levels- that is a sense of community.

\section{ASSUMPTIONS AND RATIONALE FOR STUDY}

This study was motivated by a commitment to developing innovative practical-based teaching tools for educators in order to help them engage and motivate my students. One of the study's major goals was to examine and discuss how music can be used in a college classroom to motivate students and increase piano performing skill. As a former teacher I had implemented this pedagogical strategy and wanted to test its portability. Therefore, The researcher have initiated the study assuming that any teacher could implement a practical-based lesson and have a successful experience with his/his students regardless of skill level, or musical ability. Accordingly, the researcher has chosen to look at 2nd year students (in music department).

The problem which exists in my classroom situation was serious and it needs an immediate solution for it. Since there were students taking a course piano, so to achieve their goal students should practice finger exercise. But the present situation is not satisfactory. Most students are in problem of finger practice and piano sound identification performance. All the above reasons pushed me to conduct this action research.

\section{STATEMENTS OF THE PROBLEM}

The problem in dealing with music education as a major aspect of art education is lack of available instruments for practical instruction. The best models come from practical philosophy and, most directly, programs designed to foster philosophical inquiry with students and others who are native about philosophy. Some argue that music students are naturally philosophers because of their sense of wonder and constant inquiry about things adults take for granted. Curriculum materials and pedagogical methods that have proved valuable in fostering philosophical inquiry and reflective thinking with students share two major characteristics (Aristotle).Most musical activities are ask to develop psychomotor domain with supporting by musical instrument. (Hagerman, 1988) although realize that a typical college music education course or reading 
essays about music education is easier than that of playing piano. On an individual basis offers little sense of how such activity is supported by piano instruments.

Nowadays, music education becomes one of the popular subjects in the world as well in our country, different universities take responsibilities to give training and its function is tremendous in the development of the country. Because of such reason music education became a separate subject from grade five through grade eight having its own curriculum as well as colleges. But considerable problem arose in the teaching learning process of the subject matter. Stockholders are not seen while exploiting the benefits of music education partly because in numerable problems encounter the teaching of music education Thus, initiated and identify the problems and to suggest possible solutions from the findings. The problem of piano finger practice and sound identification is not an easily solved problem and harm all students who joined in aesthetics and physical education department in cluster stream. Because of piano course is the basic course of all students for other practical music course in our college like traditional instruments, reading notes, solfeggio training (rhythmical dictation, melodically dictation sight reading) Therefore, to investigate the underlying reasons and solve the problem accordingly The researcher have raised the following questions.

1. How can I develop activities in finger exercise and sound identification activities in piano class?

2. How student's finger exercise problem of piano playing will solve?

3. How can I solve lack of instrument for solving finger exercise and sound identification problem of music students?

4. To what extent students provide mechanisms for themselves with finger exercise and sound identification problem?

\section{RESEARCH QUESTIONS}

This research was used two leading questions:-

1. How problems of students' finger practice and sound identification improve.

2. What mechanism is the best to solve the existing finger practice and sound identification problem?

\section{PURPOSE OF THE STUDY}

The main purpose of this study was finding mechanisms for my students' finger practice and sound identification problem by replacing the piano with locally available resources to solve students' finger practice and sound identification problem. And develop students' finger exercise activities by identifying and designing deferent mechanisms which fit with my students.

The specific purposes were:

1. Investigating different mechanisms to help students develop finger practice and sound identification to perform in a piano course.

2. Maximizing the level of performing scale and sound identification with piano.

3. Assessing the status of college support for music students by fulfilling musical instruments and substitute real piano with human made piano to solve the problem for helping students' finger practice and sound identification.

4. Trying to use extra time for practicing piano for students?

\section{THE RESEARCH METHODOLOGY DESIGN OF THE STUDY}

A mixed method approach(qualitative and quantitative) allows a research to collect a variety of data and make deeper, more meaningful connections between theoretical and practical aspects than the use of one method alone

\section{RESEARCH PARTICIPANTS}

Participants in the study were twelve second year cluster regular aesthetics students and two specially trained students from thirty two(selected for peer tutoring), which nine were males and three were females, as well as one music teacher researcher. Twelve students mean $37.5 \%$ chose to participate in the study from the whole class. In order to evaluate the outcome of the intervention two external observers were participated who are music professionals' (one male from zone cultural office music officer and one female music officer in city administration) were participated in the research. Generally fourteen students were participated from the total population of thirty two students and two external observers (one male and one female) were participants of the research.

\section{SAMPLING TECHNIQUES SAMPLE SIZE}

AND

Participants of this research was selected by using purposive sampling since selecting students within the problem of piano finger practice and sound identification were selected by using the following steps.

Teach students for four consecutive classes and observe their finger position and compare with others.

Let all the class students to write the name of the sound on their exercise book when I was playing piano. Then students identified only one sound per each tetra chord were selected for my research.

Two students who were specially trained selected because of the researcher have an information about them that they play piano in amateur clubs in town.

\section{DATA GATHERING INSTRUMENTS AND PROCEDURE}

The following instruments were the main data collection tools for my research.

i. Both close ended and open ended were used

ii. Observation was used to gather real information about the problem before and after intervention.

iii. Video recording and photographing for better analyzing obtained data before and after intervention both photograph and video were used to gather and evaluate the practical data.

iv. Unstructured Interview:-Ten students were interviewed during the time of data collection and after the intervention.

\section{DATA ANALYSIS TECHNIQUES}

The data collected by different instruments were analyzed by using both qualitative and quantitative data analysis techniques based on the nature of the data.

a. Qualitative data analysis techniques:-from qualitative way of data analysis narration, interpretation and direct quotation were used to analyze the data collected by observation, video recording, photograph, open ended and closed ended questionnaires 
b. Quantitative data analysis techniques: - percentage and frequency were used to analyze which was collected by questionnaires.

The above data analysis techniques were used before and after intervention to cheek the results of action taken not only by me but observations were used by two external observers.

\section{DATA ANALYSIS AND PRESENTATION OF RESULTS}

In this section the data gathered from the participants was analyzed and presented.

Video Data: When looking at the video data there was a steady increase in playing time until the final two weeks, which were after piano performance, and at a time when review of the piano performance occurred. Overall the proportion of class time spent in instruction and with class management stayed relatively even. Time spent making announcements and completing research forms varied throughout the study. The most interesting finding relates to the practicing time was that students practice by their own mobile and locally available piano and the researcher have recorded them secretly to analyze the changes. "Practice" time seems to increase from $15 \%$ to over $40 \%$ of class time, however this is misleading. Confusion resulted due to assigning too many activities to the"practical"category. Time spent in individual practice was increased by peer tutoring.

The proportion of instructional time spent in practical instruction was totally varied from the previous time, since the researcher have taken some training for the specially trained students and the training for their friends. So this increases the practical instructional time of students. The very important point that the researcher have observed was the importance of peer tutoring in solving the problem. Students were asking different questions and helps from their friends without any frustration.

Table 1 Motivation and Students learning piano

\begin{tabular}{|c|c|c|c|c|c|}
\hline \multirow[t]{3}{*}{ No } & \multirow[t]{3}{*}{ Item } & \multicolumn{4}{|c|}{ Response } \\
\hline & & yes & & No & \\
\hline & & № & $\%$ & No & $\%$ \\
\hline 1 & $\begin{array}{l}\text { When teachers motivate students they perform piano } \\
\text { better }\end{array}$ & 2 & & 10 & \\
\hline 2 & Teacher relation affect students learning & 12 & 100 & 0 & 00 \\
\hline
\end{tabular}

Table 2 Students' mobile ownership information

\begin{tabular}{|c|c|c|c|c|c|}
\hline \multirow[t]{3}{*}{ No } & \multirow[t]{3}{*}{ Items } & \multicolumn{4}{|c|}{ Response } \\
\hline & & Yes & & No & \\
\hline & & № & $\%$ & No & $\%$ \\
\hline 1 & Do you have mobile phone & 11 & 91.66 & 1 & 8.33 \\
\hline 2 & Have you used your mobile as a piano & $\mathbf{0}$ & 00 & 12 & 100 \\
\hline
\end{tabular}

As table 1 shows motivation and teacher students' relation affect students' practical piano course learning. Motivation is an important contributor to academic achievement (Ames, 1990). Alderman and Maehr (1994), declare that motivation is specifically a key issue for college students. It is a critical time in these students' lives because the $2^{\text {nd }}$ year students are students make important decisions - such as what type of focuses they will be in the future and what careers they will pursue (Ander man and Maehr, 1994). Therefore, it is important that student motivation for learning be increased starting the $1^{\text {st }}$ and $2^{\text {nd }}$ year in college in order to have successful students who value a commitment to life-long learning and the attainment of skills (Ames, 1990).Often the reputation of a college is based on student achievement as determined by standardized test scores. However, we must look for more than student achievement when evaluating how our students are doing in practical skills. Building a student's commitment to learning, attaining skills, and being open to the process of education are all-important for students to be successful in the future (Ames, 1990). Students who into upper level piano courses in college because they want to learn more, and not because they believe they can simply be successful is an example of students' making intrinsically motivated decisions and is a sign of students being open to the process of education (Ames, 1990).These are the types of students who were the leaders in the 21 st century. Colleges are social environments, places wise we need to appeal to students as unique and complex individuals, to meet them on their level in order to make a connection. When we fail to motivate students, or meet them on their level, we run the risk of their being is-engaged or dismissed. Generally by motivating students and create a good relationship the researcher have helped my students depending the data which was given from them.

The data in table 2 were use full to organize learning piano by using their own mobile without any additional cost. Almost all 
(11) students who were the participants of my research have a mobile phone and the researcher have installed the piano setup on their mobile. After installing soft ware all students used their mobile as piano where ever they go. This mechanism designed because of eleven students out of twelve students has a mobile phone.

Table 3 indicates that one student chose more than one item which affects their piano performing skill and sound identification. The most critical problem for the students were lack of instrument and lack of extra time to practice daily.Then I am expected to design the solution cooperating with the students to solve the existing problem. Generally from the above information The researcher have got that solving lack of instruments, shortage of time for practice and motivate them to practice needs solution and I should have planed an action to implement.
Depending on Table 4 gathering the solution from the students response they list only one solution but for data analysis The researcher have chosen the most applicable and reliable data for solving the problem means all of the participants believed that in order to improve piano skill they believed that only increasing instructional time was the solution 'for the problem. This has an implication about students that they haven't any information about using mobile, using human made piano and using computer was the best solution. After the researcher has obtained this data the researcher have properly implemented the selected solution and how the solution was important will deal in next chapter. In the previous time almost all students agreed that they haven't information about using mobile as piano. This implies that the data of table 4 is expected.

Table 3 Source of Student's Problem

\begin{tabular}{llll}
\hline No & Items & Response & \\
& & No & $\%$ \\
\hline $\mathbf{1}$ & Students have problem of performing piano and sound identification because & \\
A. Lack of instruments & $\mathbf{1 1}$ & $\mathbf{9 1 . 6 6}$ \\
& $\mathbf{1 0}$ & $\mathbf{8 3 . 3 3}$ \\
& B. Lack of practice Time & $\mathbf{1}$ & $\mathbf{8 . 3 3}$ \\
C. Shyness & $\mathbf{0 0}$ & $\mathbf{0 0}$ \\
D. Lack of interest & $\mathbf{9}$ & $\mathbf{7 5}$ \\
\hline
\end{tabular}

Table 4 Student's alternatives to solve the existing problem

\begin{tabular}{llll}
\hline No & Items & Response & \\
& & No & \% \\
\hline $\mathbf{1}$ & In what mechanism we solve the existing problem and increase piano skill? & \\
A. using our mobile & $\mathbf{0 0}$ & $\mathbf{0 0}$ \\
& \multicolumn{1}{c}{ Bo } & $\mathbf{0 0}$ \\
& C. Using human made piano & $\mathbf{0 0}$ & $\mathbf{0 0}$ \\
& D. Increasing instructional time & $\mathbf{1 2}$ & $\mathbf{1 0 0}$ \\
\hline
\end{tabular}

As we have seen in table 5 most of my students have problem of identifying piano sounds per $1^{\text {st }}$ and $2^{\text {nd }}$ tetra chord. Since the students answer for second tetra chord was the same as $1^{\text {st }}$ tetra chord no need of presenting $2^{\text {nd }}$ tetra chord was necessary. $75 \%$ of the students were identified only one sound out of four sounds. But students are expected to identify at least three sounds per $1^{\text {st }}$ and $2^{\text {nd }}$ tetra chords.

\section{SELF MOTIVATION}

In traditional learning, the desire to make music comes from motivational stimuli provided by the musicians and contexts of the learner's home and classroom. If the home and college of the learner have not provided the instrument necessary for such motivation, the teacher is required to do so in the non-traditional context of the school classroom. As piano course is practical it also includes body contact means the teacher expected to hold students finger to adjust their finger position. Then as my students believed that lack of teachers' motivation decrease their interest and performance of piano skill with sound identification. So, I should have motivated my students during piano practice because $100 \%$ of students respond likewise.

From table 6, The researcher has concluded that taking steps and creating awareness about the importance of using mobile as piano were very important. So I should have given them the steps of using piano on their mobile phone, the representation of mobile keys and install soft ware if they don't have on their mobile.

Open Ended Response Items. The open-ended items asked students what they enjoyed about piano class and what they would change. Two clear thematic categories emerged from the pre-survey data related to students' "enjoyment": (a) Playing 
and (b) Class Environment. Since students' suggested changes to our piano class at the beginning of the study were not implemented during the study, the new themes emerging from the post-survey were assumed to be a result of the study. The themes emerging from the post-survey item related to" enjoyment" was similar to the pre-survey results. "Playing" was again the most dominant sub-theme which included: (a) playing music; (b) playing fun songs; (c) playing my instrument; (d) playing well (new answer); and (e) learning more music. "Class environment" was the second most prominent response with all the pre-survey responses recurring, in addition to "band trips" and "everything" being included as aspects of the piano program that students enjoyed. There were 4 students who chose not to respond to this question on the post-survey. In response to being asked what students would change, pre-survey data was categorized into four themes: (a) Practical Assignments; (b) Class Structure; (c) Music; and (d) Nothing. The post-survey responses indicating students' desired changes resulted in similar categories to the pre-survey responses, with two additional themes. Theme categories related to "change" included: (a) Practical Assignments, (b) Class Structure, (c) Music, (d) Nothing, (e) Teacher, and (f) No Response. The practical assignment, again, suggested having no more practice records. Practice records are a student's written calendar documenting their minutes spent in home practice. It is interesting to note that compared to 11 students who wanted this assignment eliminated prior to the study only 4 students mentioned it during the post-survey. Changes to our class structure included suggestions for: (a) learning more about my instrument; (b) increasing class time; (c) improving student listening notes; (d) working on breathing more to sing; (e) changing the seating plan; (f) being videotaped; and (g) increasing talking time about sound melody. These responses were more specific to class content than the corresponding pre survey responses. It might be inferred that students were more aware of specific tasks being accomplished during each class theoretically but not practically.

Table 5. Students listening skill per $1^{\text {st }}$ Tetra chord

\begin{tabular}{llll}
\hline No & Items & Response & \\
& & No & \% \\
\hline $\mathbf{1}$ & How Many sounds do you hear per 1 $1^{\text {st }}$ tetra chord? & & $\mathbf{7 5}$ \\
& A. One & $\mathbf{9}$ & $\mathbf{1 6 . 6 6}$ \\
& B. Two & $\mathbf{2}$ & $\mathbf{8 . 3 3}$ \\
& C. three & $\mathbf{1}$ & $\mathbf{0 0}$ \\
& D. Four & $\mathbf{0}$ & $\mathbf{1 0 0}$ \\
& $\begin{array}{l}\text { Does your motivation affect your sound identification } \\
\text { and finger practice? }\end{array}$ & $\mathbf{1 2}$ & \\
\hline
\end{tabular}

Table 6. Students' mobile knowledge

\begin{tabular}{llllll}
\hline No & Items & \multicolumn{3}{c}{ Responses } \\
& & yes & & No \\
& & No & $\mathbf{\%}$ & No & \% \\
\hline 1 & Have you an information about using mobile as piano & 00 & 00 & 12 & 100 \\
2 & Do you know steps in mobile for using piano sounds & 00 & 00 & 12 & 100 \\
\hline
\end{tabular}

Students move place to place with their mobile phone so the researcher have shown any position on their mobile phone The most useful and applicable strategies' used to solve the existing problem are shown here.

\section{MAJOR FINDINGS}

Based on the data that the researcher have collected from the participants the following points were major findings

- Students have a problem of finger practice and sound identification.

- Lack of computer skill to use rocket system.

- $\quad$ Lack of knowledge and skill in using mobile including its steps.

\section{ACTION STRATEGIES, IMPLEMENTATION OF ACTION STRATEGIES AND EVALUATION OF ACTION STRATEGIES}

Proposed Action Strategies

The actual action plan for implementation was prepared on the basis of the findings of my research. But depending on my opening observation during my frequent teaching and video data on the college music students (piano course) and the research questions The researcher have raised, The researcher have proposed the following actions for implementations. 
1. To improve poor performer students in a piano course The researcher have proposed

* Systematize awareness training about the use of finger practice for other piano skills.

* Reorder the classroom setting arrangements of instruments for group use of depending on octave system.
2. To help the college music students get assistance from themselves and help by others, I was

* Invite two outside observers (music officers) to observe when students perform piano and sometimes assist them.

Push students to find solution by themselves.

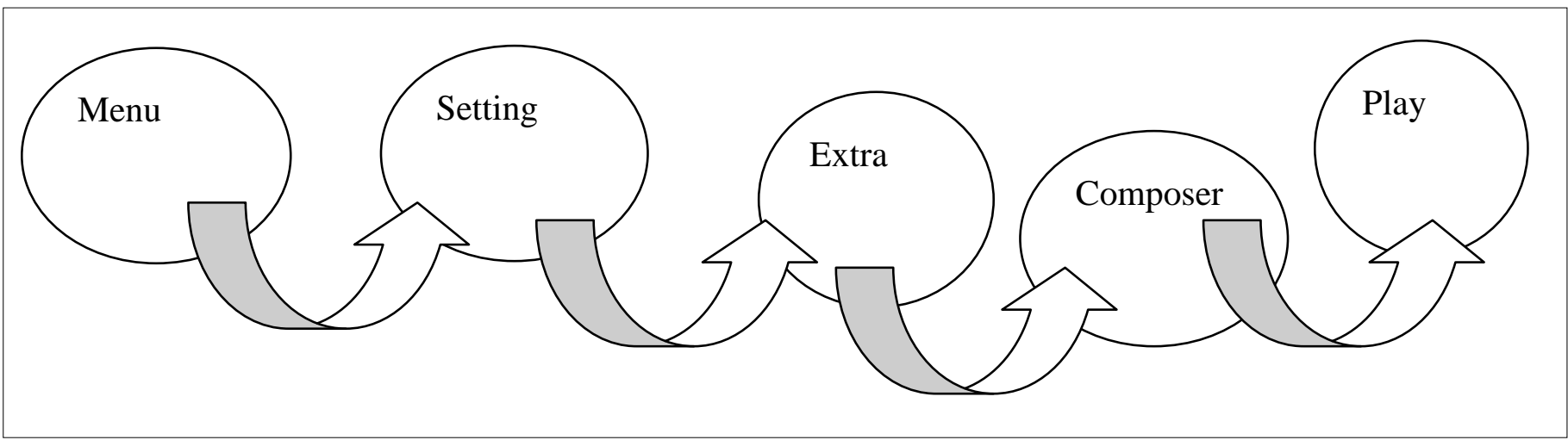

* Assign two students for peer tutoring(have special training).

3. To solve the problem that comes from lack of piano, I have proposed

* Prepare artificial pianos from different materials.

* Introduce exercising piano by their mobile.

* Give sound training by laptop rockets system.

4. To maximize time given for piano course, The researcher have

- Adjusted extra time for students

* Advice students use artificial piano in their home and class.

5. To solve the problem of teacher relation The researcher have proposed to:-

* Announce to students that piano needs friendly relationship so I believe that after implementing this action the relationship between me and my students will change. This stratagem designed because of students act like what they act in theoretical subjects, but just it should be different even in piano course body contact is mandatory to help finger practice of students.
* Inform asking question in any practical aspect from the teacher is helpful so push students to ask any practical questions.

Students move place to place with their mobile phone so the researcher have shown any position on their mobile phone Using the above explanations and instruction students have used their mobile for playing piano without any additional expense. The changes come from using this method was addressed in the evaluation part and all mobiles which installed the soft ware were functional.

\section{STEPS USED TO PLAY PIANO ON OUR MOBILE}

Since students have a problem of using mobile as piano the researcher have believed that giving the necessary steps were mandatory. Because students want to use these kinds of piano which is prepared by themselves from locally available materials, the piano has good model for finger practicing and it includes all parts of piano which is used to finger practice and the researcher have shown the parts and how can they play. As indicated by the arrow the piano has flat keys, sharp keys (white keys and black keys) to practice on it. The only limitation that has observed from using these kinds of piano was that isn't sound supported but the researcher has planned to solve the problem of sound by using mobile after finger practicing.

Table 7 Changes come from peer tutoring

\begin{tabular}{lllllll}
\hline No & Items & $\mathbf{1 0 0 \%}$ & $\mathbf{7 5 \%}$ & $\mathbf{5 0 \%}$ & $\mathbf{0 \%}$ & Other specify \\
\hline 1 & $\begin{array}{l}\text { Students have got benefits from student to student's } \\
\text { training. }\end{array}$ & 7 & 4 & 1 & -- & --- \\
\end{tabular}




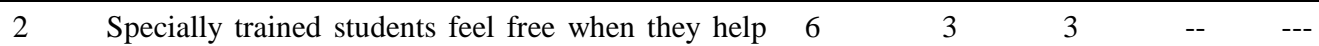
their friends.

Table 8 Main points and changes before and after intervention, performing scale of $1^{\text {st }}$ tetra chord

\begin{tabular}{llllll}
\hline No & Activities performed & \multicolumn{2}{c}{ Before intervention } & \multicolumn{2}{c}{ After intervention } \\
& & In No & In \% & In No & In \% \\
\hline 1 & Number of notes press per Minuit in $1^{\text {st }}$ tetra chord. & 2 & 50 & 4 & 100 \\
2 & Number of sound hear per minuet & 1 & 25 & 3 & 75 \\
\hline
\end{tabular}

\section{IMPLEMENTATION OF ACTION STRATEGIES}

To improve the low performing of students in piano skill and sound identification different actions were implemented in different phases as presented below.

My action implementation have had three phase

- Implementing the $1^{\text {st }}$ action strategies

- Solve the unsolved problem by using another mechanism

- Planning for the future

\section{FIRST PHASE IMPLEMENTATION}

In this phase different actions were implemented that is systematize awareness training about the use of finger practice for other piano skills and Reordered the classroom setting arrangements of instruments for group use of depending on octave system. These actions were very important for students learning piano since the $1^{\text {st }}$ orientation and setting arrangement were the basic steps in piano playing.

\section{INVITE TWO OUTSIDE OBSERVERS (MUSIC} OFFICERS)

To observe when students perform piano at the beginning The researcher have invited two music officers and they observe my students when they played piano and identified piano sounds and the researcher have recorded for further analysis.

\section{ASSIGN PEER TUTOR}

Since students were afraid of their teacher when he touch their hand (Davidson, J.W and SMITH, J.A. (1997). The researcher have preferred assigning two specially trained students to give tutorial up to students will familiar with helping of teacher by holding their hand.

\section{PUSH AND MOTIVATE STUDENTS FINDING} SOLUTION BY THEMSELVES

As students should participate in solving the problem the researcher have invited them to find the solution for the problem. Students were active participants in the process of solving the problem by designing different mechanisms.

PREPARE ARTIFICIAL PIANOS FROM DIFFERENT MATERIALS

There was a great problem related with lack of piano in the teachers college DAVIES, C. (1992). To solve the imbalance number of piano in ratio of students selecting possible mechanisms were needed. The only and best solution that the researcher have found from the data and my experience was preparing artificial piano from locally available materials. The piano was included flat keys, sharp keys and natural keys which are needed for finger practice. The only limitations the researchers have observed from this piano were no produce of sound for sound identification.

INTRODUCE FINGER PRACTICE AND SOUND IDENTIFICATION PIANO BY THEIR MOBILE

The data gathered from students tolled to me that all students weren't informed about the use of their mobile for piano finger practice and sound identification. Then I am expected to introduce and show how they can use mobile for piano use without any additional cost. The best and strong side of using mobile was including both finger practice and sound identification. Eleven students have their own mobile then they can practice in their home by using their leisure time. The problem existed during use of mobile was the different application of Nokia and China mobiles.

Table 9 Training level of satisfaction

\begin{tabular}{llllll}
\hline No & Items & \multicolumn{2}{c}{ After intervention } & & \\
& & \multicolumn{2}{c}{ Yes } & No \\
& & In No & In \% & In No & In \% \\
\hline 1 & Have you satisfied in the training? & 12 & 100 & 00 & 00 \\
2 & Are you interested to continue this training? & 12 & 100 & 00 & 00 \\
\hline
\end{tabular}

\section{GIVE SOUND TRAINING BY LAPTOP ROCKETS SYSTEM}

Rocket system is the best method for identifying piano sounds in different octaves Deliege, I and sloboda, J. (1996). Then for my students the researcher have given training in their class by using laptop and it was successful .The main problem that the researcher have faced was students' lack of piano skill. When the researcher has designed this method I think that students may practice in the library by used headphone to avoid disturbing others. Due to students lack of computer skill I am expected to design other mechanisms. 


\section{ADJUSTED EXTRA TIME FOR STUDENTS}

Piano course needs a long time for both finger exercise and sound identification (Groelng, C. 1977). The real situation in our college is that lack of piano is common problem in relation with number of students. To address all students depending on the given credit hour adjusting extra time were mandatory and students also believed that adjusting extra time was needed. By implementing this method students problem was solved but there were a solved problem which needs another extra time for the future.

\section{ADVICE STUDENTS TO USE ARTIFICIAL PIANO IN THEIR HOME AND CLASS}

After preparing artificial piano students should have used in their home to developed performing skill of piano and sound identification. Since preparing artificial piano shouldn't ask any cost means prepare from locally available materials each students can prepare it.

\section{CREATE FRIENDLY RELATIONSHIP WITH MY STUDENTS}

Most practical subjects needed friendly relationship between teachers and students (Gruson, L.M 1988). Piano is one of the music course covered by practical aspects so, in order to achieve the objective the teacher should help students even by holding their hand. During this time, if students afraid of their teacher their hand may not placed in the right way. In the $1^{\text {st }}$ phase implementation all problem of students' relation with teacher was not solved and it needs other implementation.

\section{ACCEPT ANY QUESTION AT ANY TIME AND HELP} THEM OUT OF THE CLASSROOM

I can help them at any time and place because their mobiles were functional for piano use and the researcher have informed them asking only in the class isn't needed starting from the time of mobile functioning.

\section{SECOND PHASE IMPLEMENTATION}

During the $1^{\text {st }}$ phase implementation the following problems was existed still or was not solved i.e.

- Lack of students' computer skill to use rocket system.

- Difference of application between Nokia and China mobile.

- $\quad$ Problem of artificial piano not supported for solving sound identification problem.

- Students and teacher relation still was not friendly

- Lack of class for practicing since it disturbed other nhibouring class.

\section{SOLVING LACK OF COMPUTER SKILL}

The researcher has believed that no need of computer skill mandatory. The researcher has given the steps that how they can have used piano when computer is available.

Table 10. Evaluation of changes

\begin{tabular}{llll}
\hline No & Activities performed & Before intervention & After intervention \\
& & Time & Time \\
\hline 1 & Time taken to perform $1^{\text {st }}$ tetra chord & 5 mins & 2 mins \\
2 & Time taken for playing scale & $12 \mathrm{mins}$ & 3 mins \\
\hline
\end{tabular}

\section{SOLVING APPLICATION DEFERENCE BETWEEN NOKIA AND CHINA MOBILES}

To make the application the same, since China mobiles accept Nokia piano application software the researcher have formatted China mobile and substituted piano composer soft ware with Nokia piano soft ware.

\section{ARTIFICIAL PIANO WASN'T SOUND SUPPORTED}

As the data obtained shows most students (11sts) have mobile phone and it is used to practice both finger and sound they can use their mobile when they perform on the artificial piano. The second method was that students can use sound training by recording sounds from the real piano. The only limitation that has observed during mobile phone using was lack of space for putting their fingers on mobile keys.

\section{THE $3^{\text {RD }}$ PHASE IMPLEMENTATION (PLANNING FOR THE FUTURE)}

- Implementing another action for solving lack of computer skill.

- Finding other mechanism for sound identification of two octaves.
- Create mechanism for lack of space on mobile phone.

\section{EVALUATION OF ACTION STRATEGIES AND IMPLEMENTATIONS}

Subsequent or amidst of execution of the wished-for actions the researcher have collected data to check whether or not my interventions have brought the expected change (improvement of music students in finger practice exercise and sound identification). Thus,

I. To the presentation change that comes because of giving training about finger position and the help of specially trained students respectively, The researcher have interviewed both groups on selected issues related to the area under study which means I was interview both specially trained students and non training students.

We can evaluate that the training by specially trained students was so important in increasing their piano performance.

II. To check whether or not the specially trained and non trained groups of students enhanced their dealings in the in-class and out of class activities the researcher have 
observed students when they involve in piano playing. In the teaching learning process and in preparation of artificial piano. In the preparation of piano not only selected students but also other students participate actively. This shows all students were interested in preparing and using artificial piano.

III. To assure whether or not the researcher have used the new teaching strategies that can help low performing students and other groups cooperatively the researcher have made frequent classroom observations of students.

As we have seen from table 10 we can understand that student's achieve a great change after intervention. So, the solution that the researcher has implemented was so successes full and the researcher have cheeked the change face to face. In addition to this the two outside observers

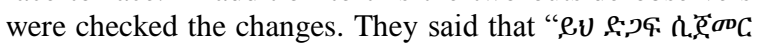
幺?

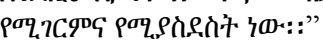

IV. To assess the changes that come on the college music students in supporting low performing students interact with specially trained students The researcher have organized focus group discussions

V. If my evaluation witness improvement of low piano performing students with specially trained student's incollege music activities, the process were cease here. But if all my interventions have seldom improved the situations The researcher have proposed other actions and continue my efforts until the problem The researcher have raised solved.

VI. I have prepared an artificial piano cooperating with my students and let them to practice on it. The changes that have obtained by using this piano have evaluated in the following table and progress picture of finger position.

The above table is used as wetness for achieving changes by the help of artificial piano. Before the intervention students have taken more time to perform the whole scale and tetra chords. Five minutes for tetra Artificial piano chords and twelve minuets for scale performing were used before intervention but after my intervention five minutes minimize to two minutes and twelve minutes minimize to three minuets so the change were so admirable and gives me pleasure.

\section{Student's Progress starting from the Begging}

As the figure 3 and 4 shows the principle of putting fingers on the piano and what the students perform was different so by implementing the methods that the researcher have

Figure 5, 6 and 7 were referring for us about the recorded progress of the students achieved by intervention selected students achieve a big progress the progress evaluation will present as follows.

As it compares with figure 3 the researcher have observed good and initiated changes in finger position as well as the speed of performing piano. Here six fingers of students were in problem out of ten fingers and when they put on the piano their hand was shivering

The problematic fingers decrease in to four in number and the speed also becoming faster than the previous. Thus if I continue the action taken on my students their performance of playing skill and sound identification will also increase and I would like to implement the next steps to help them.
It seems reach at the excellent position of playing scale and other practicing actions should have been continuing until they become perfect. Even student's motivation and interest to play piano and sound identification training increase time to time.

As the picture shows us and the theory of piano says the right position of finger putting on the piano was like wise and I am so satisfied by achieving this goal at the final steps and I want to scale up for all students this method of teaching piano.

VII. VII. The researcher have adjusted extra time to solve time shortage of students. Since piano course needs a long time of practice and it greatly help my students to reach their goals. Generally The researcher have learned the following main points from doing this research.

- The way of solving student's problem by myself.

- Systems of solving students' problem without bureaucratic approach.

- The power of students in solving their problem if the teacher plays facilitating role.

- Designing different mechanisms using locally available materials.

- The importance of collaboration for solving the existing problem.

\section{STRENGTH OBSERVED DURING MY RESEARCH}

The strength that has observed during conducting this research was, creating new mechanisms, good students performing skill after interventions, satisfaction of students and solving most problems by using newly designed mechanisms were strong side observed.

\section{WEAKNESS}

The most critical weakness observed were, lack of time for piano preparation, difference in mobile application, artificial piano wasn't sound supported, two specially students and outside observers were sometimes busy and lack of space on their mobile to put their fingers were observed during solving the existing problems.

\section{RECOMMENDED CHANGES}

The first round surveillance data that The researcher have collected during my teaching to the college aesthetics students indicate that there are about 100 students which means from year two up to year three. With a problem of performing piano in their course. However, the participants of this study was the students who were enrolled in $2^{\text {nd }}$ year extension class (38 in number) but I want to select only 12 students for this study. Other members of students in the class, the music teacher and the specially trained students who are assigned as a group leader to students who have-not any training about piano before were directly involves in this study from the total of 38 students.

The relevant data from the participants were collected using qualitative and quantitative data gathering instruments namely interview by me other music teacher and a group leader. Video data and Observation were also takes place with music teachers and students selected from the class. In line with this the following recommended changes were suggested.

- The number and type of recommended aesthetic education activities are not small. In other words, each teacher can improve and enrich the aesthetic education program in line 
with their own interests, skills and talents. In order to do this, however, teachers need to understand and appreciate art before anything else. Then piano teachers should motivate their students in order to increase piano plying and sound identification.

- For the future piano course using mobile as piano is advisable for piano sound identification. At the same time we can train our students by guessing instrument playing in their mobile.

- Specially for improving finger practice activities using man made artificial piano was a good solution for lack of piano.

- We can train more students by one computer by rocket method rocket stands for different musical sounds. All the above recommended changes were evaluated their outcome on students' piano performance.

\section{REFERENCE}

[1] Ames C (1990). Motivation: what teachers need to know. Teachers College Record, 91 (3). 261-271and http://www.pateo.nl/PDF/WhollyScience.pdf

[2] Anderman EM, Maehr ML (1999) Motivation and schooling in the middle grades. Rev. Educ. Res. 64, (2): pp.287-309.

[3] Cavitt ME (2003). A descriptive analysis of error correction in instrumental music America. New York, NY: Three Rivers Press.

[4] Davidson JW, Smith JA. (1997). A case study of 'newer practices' in music education atconservatoire level. Brit. J. Music Educ. 14(3): p.251-170.
[5] Davies C (1992). Listen to my song: a study of songs invented by children aged 5 to 7 years. Brit. J. Music Educ. 9(1): pp.19-48.

[6] Deliege I, Sloboda J (1996) (Eds.). Musical beginnings: Origins and development of music, neeyork. V3,pp 36-38

[7] Duke RA, Henninger JC (2002). Teachers' verbal corrections and observers'Groeling, C. (1977). A comparison of two methods of teaching instrumental music to do fourth grade beginners. Bulletin of the Council for Research in Music Education, 51, pp.41-44.

[8] GRUSON, LM (1988). Rehearsal skill and musical competence: Does practice make perfect?

[9] Sloboda JA (2000) Generative Processes in Music: The psychology of performance, improvisation and composition. Oxford: Clarendon Press. pp. 91-112. Oxford: Clarendon Press.

[10] 'Kalliphobia in Contemporary Art' in Art Journal v. 63 no. 2 (Summer 2004): pp. 24-35

[11] Kozol J (1991). Savage in equalities. New York, NY: Harper Collins Publishers.

[12] Kozol J (2006). The shame of the nation: The restoration of apartheid schooling in perceptions of teaching and learning. J. Res. Music Educ. 50(1), rehearsals. J. Res. Music Educ. 51(3): pp.218-230.

[13] Image of finger practice captured by Atalay Mesfin,Debremarkos Ethiopia. 